\title{
Debulking surgery for functional pleural dissemination of parathyroid carcinoma- case report
}

\author{
Sachi Kawagishi ${ }^{1}$, Soichiro Funaki ${ }^{1}$, Naoko Ose ${ }^{1}$, Kenji Kimura ${ }^{1}$, Kosuke Mukai ${ }^{2}$, Michio Otsuki ${ }^{2}$ and \\ Yasushi Shintani $i^{*}$ (D)
}

\begin{abstract}
Background: A rare cause of primary hyperparathyroidism (PHPT) is a parathyroid carcinoma. Hypercalcemia with an elevated parathyroid hormone (PTH) level seen in recurrent and metastasis disease cases is often refractory to medical therapy, thus surgical resection is recommended when possible. We performed debulking surgery for pleural dissemination of parathyroid cancer for improvement of symptoms in a patient with hypercalcemia.

Case presentation: A 30-year-old male with hypercalcemia was diagnosed with parathyroid cancer. Following surgery, intact PTH level elevation and hypercalcemia progression due to recurrent disease were noted. An active status of functional left pleural dissemination was revealed in $99 \mathrm{mTc}$-methoxyisobutylisonitrile and somatostatin receptor scintigraphy results, but not in the area of pulmonary metastasis, and debulking surgery was performed. Thereafter, the PTH level was decreased temporarily and activities of daily living improved.
\end{abstract}

Conclusion: Aggressive resection of metastatic disease in patients with a parathyroid carcinoma is taken into consideration to control hypercalcemia.

Keywords: Parathyroid carcinoma, Primary hyperparathyroidism, Pleural metastasis, Debulking surgery

\section{Background}

A parathyroid carcinoma is a rare cause of primary hyperparathyroidism (PHPT), accounting for less than $1 \%$ of all reported cases. Treatment for parathyroid cancer is generally surgical resection, though previous reports indicate that affected patients often develop recurrence and metastasis after surgery, and show a poor prognosis because of hypercalcemia and subsequent metabolic complications rather than tumor invasiveness [1]. Hypercalcemia with an elevated parathyroid hormone $(\mathrm{PTH})$ level seen in recurrent and metastasis disease cases is often refractory to medical therapy, thus

\footnotetext{
*Correspondence: yshintani@thoracic.med.osaka-u.ac.jp

'Department of General Thoracic Surgery, Osaka University Graduate School of Medicine, 2-2-L5, Yamadaoka, Suita, 565-0871 Osaka, Japan

Full list of author information is available at the end of the article
}

surgical resection is recommended when possible [2]. Herein, we report details of a patient who underwent a debulking procedure for recurrence of pleural dissemination following surgery for a parathyroid carcinoma.

\section{Case presentation}

A 30-year-old male visited another hospital with dyspnea, polydipsia, and polyuria, as well as vomiting and joint pain, and had experienced weight loss of $25 \mathrm{~kg}$ during the previous year. Laboratory testing showed serum calcium at $20.6 \mathrm{mg} / \mathrm{dL}$ and PTH elevated to $10,380 \mathrm{pg} /$ $\mathrm{mL}$, and parathyroid cancer was strongly suspected after imaging was performed. The patient was referred to our hospital, where en bloc resection of the tumor located along the left lobe of the thyroid gland and neck dissection were performed, and pathological findings

(c) The Author(s). 2021 Open Access This article is licensed under a Creative Commons Attribution 4.0 International License, which permits use, sharing, adaptation, distribution and reproduction in any medium or format, as long as you give appropriate credit to the original author(s) and the source, provide a link to the Creative Commons licence, and indicate if changes were made. The images or other third party material in this article are included in the article's Creative Commons licence, unless indicated otherwise in a credit line to the material. If material is not included in the article's Creative Commons licence and your intended use is not permitted by statutory regulation or exceeds the permitted use, you will need to obtain permission directly from the copyright holder. To view a copy of this licence, visit http://creativecommons.org/licenses/by/4.0/ The Creative Commons Public Domain Dedication waiver (http://creativecommons.org/publicdomain/zero/1.0/) applies to the data made available in this article, unless otherwise stated in a credit line to the data. 
confirmed a diagnosis of parathyroid cancer. Following surgery, radiation therapy with 66 Gy was performed. Thereafter, PTH was $100 \mathrm{pg} / \mathrm{mL}$ and the patient was followed in an outpatient setting.

At 32 months after surgery, blood test results showed re-elevation of $\mathrm{PTH}$, and chest computerized tomography $(\mathrm{CT})$ revealed bilateral multiple lung nodules and left pleural dissemination. Symptoms of hypercalcemia also progressed, thus the patient required hospitalization because of progression of subjective symptoms. Treatments for hypercalcemia with intravenous hydration, diuretics, and administration of cinacalcet (a secondgeneration calcimimetic), as well as denosumab (fully human monoclonal antibody that binds the cytokine receptor activator of $\mathrm{NF}_{\kappa} \mathrm{B}$ ligand), octreotide (long-acting somatostatin analogue), and zoledronic acid (bisphosphonate) were performed. However, elevation of PTH level and hypercalcemia progressed. Chest X-ray findings showed massive pleural effusion (Fig. 1a). Results obtained with both $99 \mathrm{mTc}$-methoxyisobutylisonitrile (MIBI) scintigraphy and somatostatin receptor scintigraphy revealed functionally active status lesions in left pleural dissemination, but not in the area of pulmonary metastasis (Fig. 1b, c). Radiation therapy with 60 Gy for left pleural dissemination was performed, though response was poor. The patient was then referred to our department for surgical resection of left pleural dissemination at 37 months after the initial surgery.

Volume reduction of left pleural dissemination to control hypercalcemia was performed via 5 th intercostal space thoracotomy. There were several hypervascular tumors $3-5 \mathrm{~cm}$ in size disseminated throughout the left thoracic cavity. The pleural tumor was resected using parietal extra-pleural dissection as much as possible. (Fig. 2a, b). We cut into the tumors in order not to damage the pulmonary parenchyma. We cut into the tumors so as to not damage the pulmonary parenchyma. The edges of the tumors on the parietal and visceral pleura were cauterized for hemostasis, while ablation was also done using a soft coagulation system that delivers a computer-controlled low voltage level without electrical discharge. The operation duration was $240 \mathrm{~min}$ and blood loss was $3100 \mathrm{~mL}$. The pleural tumors were hypervascular. Also, we could not observe tumors in the pleural cavity at first, as they were disseminated throughout the left thoracic cavity, thus parietal extrapleural dissection was performed to remove the tumor causing massive bleeding. Chest CT results after resection showed that the functionally active site of left pleural dissemination was nearly completely excised (Fig. 2c). A postoperative pathological examination revealed findings similar to parathyroid cancer, thus the diagnosis was pleural dissemination of parathyroid cancer (Fig. 2d). PTH level was $46,800 \mathrm{pg} / \mathrm{mL}$ prior to resection of
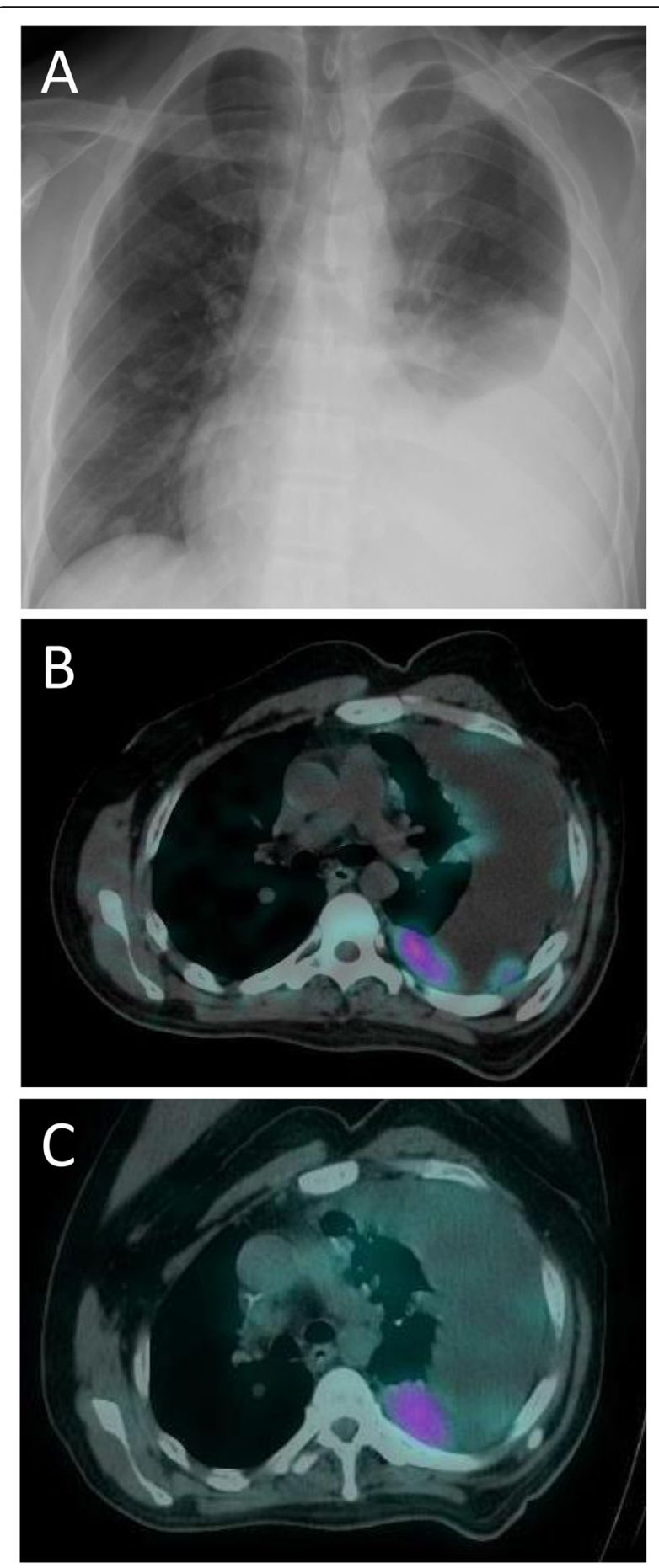

Fig. 1 Preoperative imaging findings. a Chest X-ray showing massive pleural effusion. $\mathbf{b}$ MIBI scintigraphy and $\mathbf{c}$ somatostatin receptor scintigraphy showing functionally active status in left pleural dissemination, but not in the area of pulmonary metastasis

pleural dissemination and then decreased to $7636 \mathrm{pg} / \mathrm{mL}$ on the first postoperative day. Infusion volume was gradually decreased and the serum calcium level did not increase. Hypercalcemia symptoms were improved and the 

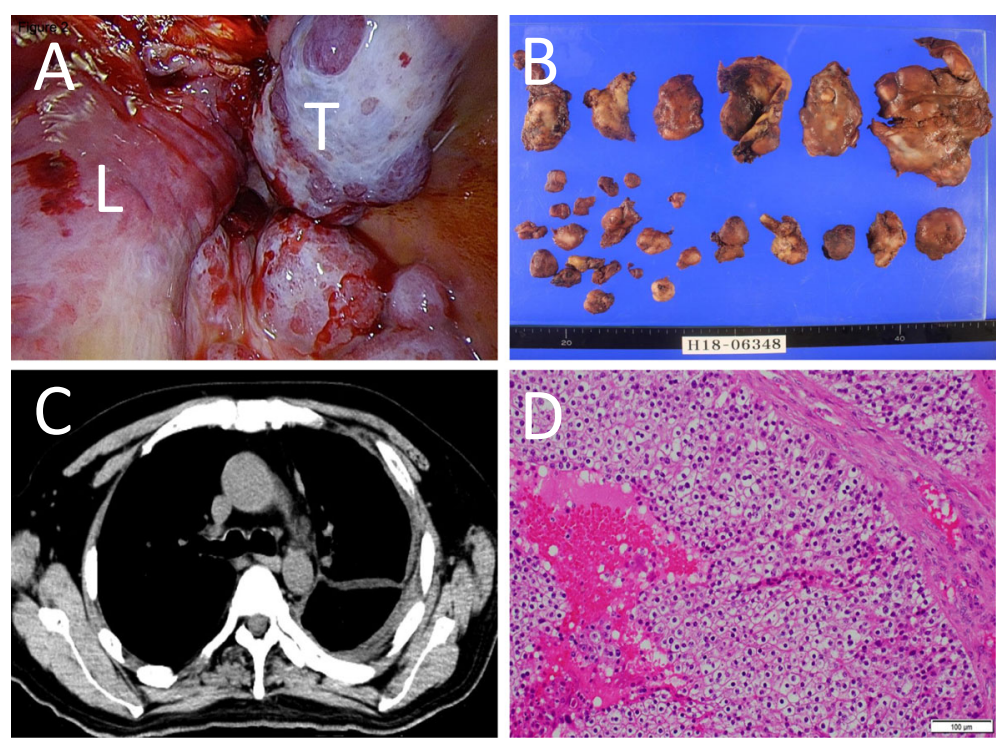

Fig. 2 a Intraoperative findings. Several tumors $3-5 \mathrm{~cm}$ in size were found in the left thoracic cavity and resected as much as possible via a thoracotomy. $\mathbf{b}$ Images of resected tumor. c Following resection. Chest CT showed that the functionally active site of left pleural dissemination was nearly completely excised. T, tumor; L, lung. $\mathbf{d}$ Pleural dissemination shown by hematoxylin and eosin staining. Tumor cells with round nuclei and lightly acidophilic cytoplasm showed a solid pattern $(\times 200)$

patient was discharged 56 days later. Under medical treatment for hypercalcemia with denosumab and cinacalcet, the PTH level gradually increased, while serum calcium level did not change. Eight months after the resection of pleural dissemination, the patient died at home from cachexia related to the disease.

\section{Discussion and conclusions}

The most common cause of PHPT is parathyroid adenoma, accounting for $90 \%$ of all cases. On the other hand, a parathyroid carcinoma is a rare type of endocrine malignancy, accounting for $<1 \%$ of all cases of PHPT, most of which show general symptoms of hypercalcemia as seen in the present patient [3]. A blood test at the time of diagnosis reveals elevated serum calcium and PTH levels to a significantly greater level in patients with parathyroid cancer as compared to those with parathyroid adenoma [4]. Some reports have noted that serum PTH serves as an excellent indicator of recurrence and metastasis after initial surgery for parathyroid cancer [5]. MIBI scintigraphy reveals uptake of PHPT, thus is useful for localization of ectopic diseases and distant matastasis [1]. Also, since a parathyroid carcinoma expresses somatostatin receptors, scintigraphy may be beneficial for showing that expression and distant metastasis related to the tumor [6].

Chemotherapy has not been demonstrated to be beneficial for parathyroid carcinoma treatment [3]. Furthermore, a parathyroid carcinoma and sites of distant metastasis are generally not considered to be radiosensitive, thus complete resection of an isolated metastatic site or pulmonary metastases after initial surgery for parathyroid cancer can control serum calcium and PTH levels [5].

To the best of our knowledge, this is the first report of debulking surgery for a patient with a wide range of pleural dissemination of parathyroid cancer. The point is that the degree of MIBI or somatostatin receptor scintigraphy uptake was useful to expect PTH production capacity of these metastatic regions in this patient. We considered that the $\mathrm{PTH}$-producing site was mainly pleural dissemination and performed resection of that as much as possible. Therefore, PTH level revealed $84 \%$ reduction after debulking surgery and we were able to decrease serum calcium level. Although debulking surgery for pleural dissemination did not achieve complete remission, discharge from the hospital to receive home medical care was possible because of improvements in subjective symptoms. Radiation therapy had poor effects in this case. It was considered that the subjective symptoms would not improve and patient prognosis would be very poor if only internal treatments such as chest drainage and pleurodesis were performed.

In conclusion, aggressive resection of metastatic disease in patients with a parathyroid carcinoma is taken into consideration to control hypercalcemia. MIBI scintigraphy and somatostatin receptor scintigraphy may be beneficial for identification of a PTH-producing site in such cases.

\section{Abbreviations}

CT: Computerized tomography; MIBI: Methoxyisobutylisonitrile; PHPT: Primary hyperparathyroidism; PTH: Parathyroid hormone 


\section{Acknowledgements}

We thank Drs. Seiji Taniguchi, and Eiichi Morii for pathologic diagnosis.

\section{Authors' contributions}

SK, MO, and YS designed the research. SK is the first author of this manuscript. YS is the corresponding author. SK, SF, NO, and YS performed the surgery. KK made a pathological diagnosis. KM and MO performed medical treatment. All authors read and approved the final manuscript.

\section{Funding}

Not applicable.

Availability of data and materials

Not applicable.

\section{Declarations}

Ethics approval and consent to participate

Not applicable.

\section{Consent for publication}

The patient provided written, informed consent.

\section{Competing interests}

The authors declare that they have no competing interests.

\section{Author details}

'Department of General Thoracic Surgery, Osaka University Graduate School of Medicine, 2-2-L5, Yamadaoka, Suita, 565-0871 Osaka, Japan. ${ }^{2}$ Department of Metabolic Medicine, Osaka University Graduate School of Medicine, Suita, Osaka, Japan.

Received: 29 October 2020 Accepted: 5 April 2021

Published online: 15 April 2021

\section{References}

1. lacobone M, Ruffolo C, Lumachi F, Favia G. Results of iterative surgery for persistent and recurrent parathyroid carcinoma. Langenbeck's Arch Surg. 2005;390(5):385-90. https://doi.org/10.1007/s00423-005-0555-6.

2. Schulte KM, Talat N. Diagnosis and management of parathyroid cancer. Nat Rev Endocrinol. 2012:8(10):612-22. https://doi.org/10.1038/nrendo.2012.102.

3. Sharretts JM, Kebebew E, Simonds WF. Parathyroid cancer. Semin Oncol. 2010;37(6):580-90. https://doi.org/10.1053/j.seminoncol.2010.10.013.

4. Fernandez-Ranvier GG, Khanafshar E, Jensen K, Zarnegar R, Lee J, Kebebew $E$, et al. Parathyroid carcinoma, atypical parathyroid adenoma, or parathyromatosis? Cancer. 2007;110(2):255-64. https://doi.org/10.1002/ cncr.22790.

5. Kim YS. Parathyroid carcinoma with lung metastasis in a thirteen-year-old girl. J Korean Surg Soc. 2012;82(6):385-8. https://doi.org/10.4174/jkss.2012.82. 6.385.

6. Storvall S, Leijon H, Ryhanen E, Louhimo J, Haglund C, Schalin-Jantti C, et al. Somatostatin receptor expression in parathyroid neoplasms. Endocr Connect. 2019;8(8):1213-23. https://doi.org/10.1530/EC-19-0260.

\section{Publisher's Note}

Springer Nature remains neutral with regard to jurisdictional claims in published maps and institutional affiliations. 